\title{
FUNCTIONAL ASSESSMENT OF ARTHROSCOPIC REPAIR FOR RECURRENT ANTERIOR SHOULDER INSTABILITY
}

Ildeu Afonso de Almeida Filho', Marco Antônio de Castro Veado², Márcio Fim³ ${ }^{3}$ Lincoln Vargas da Silva Corrêa ${ }^{3}$, Antônio Enéas Rangel de Carvalho Junior ${ }^{1}$

\section{ABSTRACT}

Objective: To clinically and radiologically evaluate patients who underwent arthroscopic surgical treatment for anterior shoulder instability by means of the Bankart technique, using metal anchors. Methods: This was a retrospective study on 49 patients who underwent arthroscopic repair of anterior shoulder instability between 2002 and 2007. The patients were evaluated using the Carter-Rowe score and the Samilson and Prieto classification. The mean age at the time of surgery was 30 years. The mean length of follow-up was 42.7 months (ranging from 18 to 74 ). $85 \%$ of the patients were male. Results: The mean Carter-Rowe score was 83 points (ranging from 30 to 100) including 31 excellent results, 7 good, 3 fair and 8 poor. Recurrent dislocation was observed in $16 \%$ ( 8 patients), and $37.5 \%$ of them were of traumatic origin. Joint degeneration was present in $32.5 \%$ of the cases, including 5 cases of grade 1, 6 cases of grade 2 and 2 cases of grade 3 . The average loss of external rotation was $12^{\circ}$ and the loss of anterior elevation was $8^{\circ}$. There was a statistically significant relationship $(\mathrm{p}<0.05)$ between arthritis and age at first dislocation, age at surgery and crackling. $92 \%$ of the patients reported high degrees of satisfaction after the procedure. Among the complications, there were two cases of stiff shoulder, one patient with prominence of the synthesis material and one case of anchor loosening. Conclusion: Arthroscopic repair of anterior shoulder instability using metal anchors was shown to be effective, with a low complication rate.

Keywords - Shoulder Dislocation/radiography; Joint Instability; Arthroscopy; Retrospective Studies

\section{INTRODUCTION}

Avulsion of the anteroinferior capsulolabral ligament complex of the glenoid, known as the Bankart lesion $^{(1)}$, was described for the first time by Perthes ${ }^{(2)}$ and Bankart ${ }^{(3)}$ at the start of the $20^{\text {th }}$ century. The role of the anterior labrum in maintaining the stability of the glenohumeral joint has been well described in the modern literature ${ }^{(4-7)}$. The insertion of the inferior glenohumeral ligament is located in the anteroinferior portion of the glenoid, and this forms the main restriction against anterior translocation of the humeral head in a position of abduction and external rotation $^{(8)}$. The treatment to be performed is defined after assessing the anatomical lesions, which could be in bones, soft tissues ${ }^{(9)}$ or both. The type of surgery to be used should, as well as repairing any lesions present, not cause damage to normal tissue. The arthroscopic method provides an effective and safe technique in these respects, unlike the open method for repairing Bankart lesions, which necessarily includes tenotomy of the subscapularis, with its possible complications $^{(10-12)}$. Today, some tendencies contrary to arthroscopic repair of Bankart lesions can still be found, but these opinions are contradicted by several studies that have shown good results from arthroscopy to treat traumatic anterior instability of the shoulder ${ }^{(10,13-16)}$. Nevertheless, the discrepancy favoring open repair that has been found has been attributed to factors such as technical difficulty, lack of surgical

\footnotetext{
1 - Shoulder and Elbow Surgeon at Hospital Felício Rocho, Belo Horizonte, MG, Brazil.

2 - Professor in the School of Medical Sciences of Minas Gerais; Shoulder and Elbow Surgeon at Hospital Mater Dei, IPSEMG, Belo Horizonte, MG, Brazil

3 - Fourth-year Specialization Student in Shoulder and Elbow Surgery, Hospital Felício Rocho, Belo Horizonte, MG, Brazil.

Work performed at Hospital Felício Rocho, Hospital Mater Dei and Hospital São José (School of Medical Sciences of Minas Gerais).

Correspondence: Rua Abel Araújo 407, ap. 901, São Bento, 30350-532 Belo Horizonte, MG. Tel/fax: (31) 3285-0347. E-mail: ildeu_almeida@hotmail.com

Work received for publication: May 4, 2011; accepted for publication: June 16, 2011.
}

The authors declare that there was no conflict of interest in conducting this work 
experience, better quality of repair and inadequate patient selection. With refinement of the technique, these factors have become modified. The aim of the present study was to clinically and radiographically assess patients who underwent Bankart lesion repair arthroscopically, using metal anchors and with or without capsuloplasty.

\section{MATERIALS AND METHODS}

Between June 2002 and June 2007, 49 patients underwent arthroscopic treatment for traumatic recurrent anterior glenohumeral instability, in three different medical centers, performed by three independent surgeons. The patient distribution according to sex and age group is shown in Table 1 . The patients included in this study had undergone two or more episodes of anterior shoulder dislocation, and the first episode had necessarily occurred due to trauma of significant magnitude. The minimum postoperative follow-up was 18 months and the maximum was 74.8 months, with a mean of 42.7 months. The following occurrences were among the exclusion criteria in selecting the patients: glenohumeral fractures and dislocations; traumatic dislocation associated with vascular or nerve injuries; fractures at other sites of the scapular belt; Hill-Sachs lesions involving more than a quarter of the humeral head; fractures involving more than a quarter of the area of the glenoid cavity; multidirectional and/or non-traumatic instability; and previous surgery on the shoulder involved.

\section{Before the operation}

Before the operation, all the patients underwent a clinical assessment to diagnose and classify the instability. Radiographic examinations were performed in the anteroposterior (true AP), scapular lateral and axillary views.

\section{Surgical technique}

The surgical procedure was performed with the patient under general anesthesia and brachial plexus blockade, positioned in lateral decubitus on the side opposite to the injured shoulder.

Table 1 - Demographic data.

\begin{tabular}{c|c|c}
\hline & Male & Female \\
\hline Number & 42 & 7 \\
\hline Mean age (years) & 31.8 & 43.5 \\
\hline
\end{tabular}

Vertical and longitudinal traction was applied on the surgical table, with the limb kept in abduction of approximately 50 degrees and flexion of 15 degrees, using fixed longitudinal traction and vertical traction with weights of 2-4 kg, by means of a specific device adapted to the surgical table.

We used a posterior portal for arthroscopy, located $2.0 \mathrm{~cm}$ distally and $2.0 \mathrm{~cm}$ medially to the posterolateral angle of the acromion. Two other portals were made in the anterior region of the shoulder, on order to place cannulae: these were always made laterally to the coracoid process in order to minimize possible vascular and nerve injuries.

Before positioning the cannulae, the joint was investigated, taking the reference point of the long tendon of the biceps and its superior labral insertion. Following this, we assessed the anterior, inferior and posterior labra, joint surfaces, ligaments, capsule, recesses and rotator cuff.

The viewing device was then taken to the anterosuperior portal and the irrigation to the posterior portal, to have a wider view of the anterior labrum. This was marked out and then surgically prepared using a shaver blade to produce a bed suitable for the reinserted capsulolabral complex to heal in. The same procedure was performed on the surface of the glenoid rim, from where the labrum had originally been deinserted. Here, in addition to debridement of the remaining soft tissues, we also used an abrasion blade to scarify the subchondral bone.

After performing the necessary debridement, we then reinserted the labrum at its origin, by means of a suturing technique with an anchor. Two to four 4.0 mm metal anchors loaded with Ethibond ${ }^{\circledR}$ number 2 thread or Fiberwire ${ }^{\circledR}$ number 2 were generally used, depending on the extent of the lesion. Capsular plication was done in conjunction with the technique of labial suturing in cases in which there had been three or more episodes of dislocation.

After placing the anchors, the portals were closed in layers and the limb was immobilized in a Velpeau sling.

\section{After the operation}

The patients remained continuously immobilized in a sling for three to four weeks, and then rehabilitation was started. From the fourth to the sixth week after the operation, immobilization was limited to activities outside of the home. After the sixth week, the patient was freed from sling use, but continued with physiotherapy 
until functional recovery of the limb had been achieved. Patients were allowed to return to contact or collision sports activities from the sixth month onwards.

\section{Clinical and radiographic assessment}

All the patients in this study were followed up for a minimum of 18 months after the operation. A questionnaire was applied to the patients during their routine postoperative follow-up. After anamnesis, they underwent a physical examination to assess their range of motion (ROM), signs of instability, pain and crepitation. The results from the operation were quantified using the Carter-Rowe score ${ }^{(1)}$ (Table 2), which is based on the criteria of instability, ROM and capacity to use the shoulder.

The positioning of the anchors and the presence of degenerative alterations were evaluated by means of radiography on the shoulder. The joint degeneration was measured using the radiographic criteria of Samilson and Prieto (Table 3).

Table 2 - Carter-Rowe score.

\begin{tabular}{|c|c|c|c|}
\hline Criteria & & Pontuação & \\
\hline \multirow{4}{*}{ Stability } & No subluxation or catching & & 50 \\
\hline & & $\begin{array}{l}\text { Catching in certain } \\
\text { positions }\end{array}$ & 30 \\
\hline & & $\begin{array}{l}\text { Subluxation (not } \\
\text { requiring reduction) }\end{array}$ & 10 \\
\hline & & $\begin{array}{l}\text { Recurrent } \\
\text { dislocation }\end{array}$ & 0 \\
\hline \multirow{4}{*}{ Movement } & $\begin{array}{l}100 \% \text { : anterior elevation } \\
(\mathrm{AE}), \text { internal rotation }(\mathrm{IR}), \\
\text { external rotation (ER) }\end{array}$ & & 20 \\
\hline & & $\begin{array}{l}75 \%: \text { ER, AE } \\
100 \%: \text { IR } \\
\end{array}$ & 15 \\
\hline & & $\begin{array}{l}50 \%: \text { ER } \\
75 \%: \text { IR, AE } \\
\end{array}$ & 5 \\
\hline & & 50\%: ER, AE, IR & 0 \\
\hline \multirow[t]{4}{*}{ Function } & $\begin{array}{l}\text { Without limitation regarding } \\
\text { work or sports }\end{array}$ & & 30 \\
\hline & Leve limitação e desconforto & & 25 \\
\hline & $\begin{array}{l}\text { Moderate limitation and } \\
\text { discomfort }\end{array}$ & & 10 \\
\hline & Marked limitation and pain & & 0 \\
\hline Total & Points possible & & 100 \\
\hline
\end{tabular}

Table 3 - Samilson and Prieto classification for glenohumeral osteoarthrosis.

\begin{tabular}{l|l}
\hline & \multicolumn{1}{c}{ Criteria (on AP X-ray) } \\
\hline Mild (I) & $\begin{array}{l}\text { Osteophytes }<3 \mathrm{~mm} \\
\text { Glenoid and/or lower head }\end{array}$ \\
\hline Moderate (II) & $\begin{array}{l}\text { Osteophytes 3-7 mm } \\
\text { Glenoid and/or lower head } \\
\bullet \text { With slight joint irregularity }\end{array}$ \\
\hline Severe (III) & $\bullet$ Osteophytes $>7 \mathrm{~mm}$ \\
& Glenoid and/or lower head \\
\hline
\end{tabular}

\section{STATISTICS}

All the statistical analysis was performed using specific calculation software (SPSS 17.0). In order to assess the degree of linear association between pairs of quantitative variables, Spearman's correlation coefficient was used. This coefficient is a nonparametric statistical tool and was used because the variables in question did not present normal distribution. To assess associations between pairs of qualitative variables, we used independence tests such as the chi-square test. In some cases, the sample size was insufficiently large for the expected frequencies all to be greater than five. In such cases, Fisher's exact test was used instead of the chi-square test.

To compare a quantitative variable with normal distribution with a categorical variable, we used ANOVA. This is a parametric test in which the null hypothesis is that on average all the treatments are equal. If there is a difference in at least one average, a multiple comparisons test is performed. In this study, the Tukey test was used.

To compare a quantitative variable without normal distribution with a categorical variable, we used the Kruskal-Wallis test. This is a nonparametric test and thus, it does not require the data to have normal distribution. It measures the distance between the medians and compares whether the variables might or might not have the same distribution. However, in comparing a quantitative variable with normal distribution with a dichotomous variable, we used the $t$ test; and if the quantitative variable did not have normal distribution, we used the Mann-Whitney test.

The significance level used in this study was 5\% (p-value $<0.05)$.

\section{RESULTS}

In the clinical evaluation using Carter-Rowe, this series gave a mean score of 83.3 points. There were 31 excellent results, seven good, three fair and eight poor (Figure 1). All the poor results were associated with renewed dislocation and were from male patients. The 38 patients with good and excellent results were followed up for an average of 42.8 months, while the average for the three patients with fair results was 47.2 months and for the eight patients with poor results, 40.3 months. The mean number of anchors was 3.0 (range from 1 to 5): 3.0 in the good/ excellent group and 2.9 in the fair/poor group. Among 


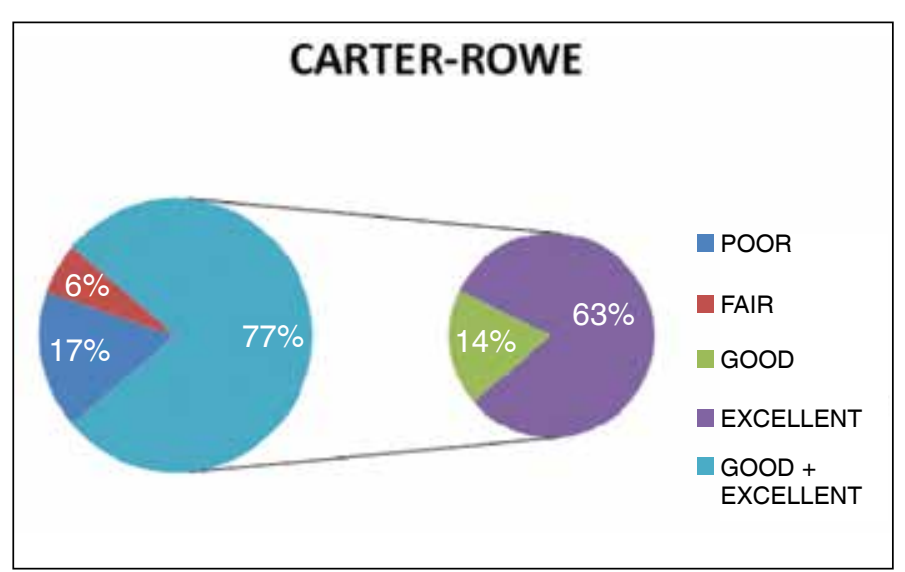

Figure 1 - Results according to Carter-Rowe score.

the patients with renewed dislocation, the number of anchors ranged from one to five (mean of three). Three of the eight cases of renewed dislocation were associated with trauma and two with sports activities without trauma; the other three were non-traumatic. There was no statistical association between renewed dislocation and the following: age at the time of the first episode; age at the time of the surgical treatment; interval between the first dislocation and the surgery; and number of episodes of dislocation (Table 4). However, even without presenting statistical significance, the risk of renewed dislocation was 2.84 times greater for patients with more than 10 episodes of dislocation after the operation. Among the seven women, four presented excellent results, two good and one fair. Among the men, 24 results were excellent, eight good, two fair and eight poor.

Analysis on the relationship between the number of anchors $(\leq 2$ or $\geq 3)$ and several variables did not produce any statistically significant results (Table 5). Likewise, in relation to the presence of prominent intra-articular anchors, none of the results from the variables tested found a $p$-value $<0.05$ (Table 6). It needs to be noted that only one case of anchor prominence was found.

In measuring the influence of sex on postoperative evolution, no divergences between male and female patients were found (Table 7). There was no difference between the sexes regarding Rowe score, renewed dislocation or presence of glenohumeral arthrosis. In this sample, all the cases of renewed dislocation were male, but the evaluation using Fisher's exact test did not show any statistical difference. Regarding arthrosis, $80 \%$ of the cases were male, but again without any evident statistical relationship.
Table 4 - Statistical analysis on the variables.

\begin{tabular}{l|l|l|l}
\hline \multicolumn{1}{c|}{ Variables } & p value & Statistical test & \\
\hline $\begin{array}{l}\text { Age at first } \\
\text { dislocation }\end{array}$ & & & \\
\hline Renewed dislocation & 0.143 & Mann-Whitney & ${ }^{*} \mathrm{NS}$ \\
\hline Arthrosis & 0.045 & Kruskal-Wallis & ${ }^{*} \mathrm{~S}$ \\
\hline Rowe & 0.398 & Spearman & ${ }^{*} \mathrm{NS}$ \\
\hline $\begin{array}{l}\text { Age at time of surgical } \\
\text { treatment }\end{array}$ & & & \\
\hline Renewed dislocation & 0.068 & $\mathrm{t}$ test & ${ }^{*} \mathrm{NS}$ \\
\hline Arthrosis & 0.001 & ANOVA & ${ }^{*} \mathrm{~S}$ \\
\hline Rowe & 0.127 & Spearman & ${ }^{*} \mathrm{NS}$ \\
\hline $\begin{array}{l}\text { Interval between } \\
\text { first dislocation and } \\
\text { surgical treatment }\end{array}$ & & & \\
\hline Renewed dislocation & 0.18 & Kruskal-Wallis & ${ }^{*} \mathrm{NS}$ \\
\hline Arthrosis & 0.983 & Kruskal-Wallis & ${ }^{*} \mathrm{NS}$ \\
\hline Rowe & 0.765 & Spearman & ${ }^{*} \mathrm{NS}$ \\
\hline $\begin{array}{l}\text { Number of episodes } \\
\text { of preoperative } \\
\text { dislocation }\end{array}$ & & & \\
\hline Renewed dislocation & 0.969 & Fisher exact & ${ }^{*} \mathrm{NS}$ \\
\hline Arthrosis & 0.106 & Spearman & ${ }^{*} \mathrm{NS}$ \\
\hline Rowe & 0.183 & Spearman & ${ }^{*} \mathrm{NS}$ \\
\hline Crepitation & 0.018 & Fisher exact & ${ }^{*} \mathrm{~S}$ \\
\hline Arthrosis & & & \\
\hline Pain & 0.329 & Fisher exact & ${ }^{*} \mathrm{NS}$ \\
\hline Arthrosis & & & \\
\hline NS not & & & \\
\hline
\end{tabular}

${ }^{*} \mathrm{NS}$ - not significant; ${ }^{*} \mathrm{~S}$ - statistically significant.

Table 5 - Stratification according to number of anchors.

\begin{tabular}{c|c|c|c}
\hline $\begin{array}{c}\text { Number of anchors: } \\
\leq \mathbf{2} \text { versus } \geq \mathbf{3}\end{array}$ & p value & $\begin{array}{c}\text { Statistical } \\
\text { test }\end{array}$ & Significance \\
\hline Rowe & 0.256 & $\begin{array}{c}\text { Mann- } \\
\text { Whitney }\end{array}$ & ${ }^{*} \mathrm{NS}$ \\
\hline Renewed dislocation & 0.321 & Fisher & ${ }^{*} \mathrm{NS}$ \\
\hline Arthrosis & 1.000 & Fisher & ${ }^{*} \mathrm{NS}$ \\
\hline Crepitation & 1.000 & Fisher & ${ }^{*} \mathrm{NS}$ \\
\hline Pain & 0.670 & Fisher & ${ }^{*} \mathrm{NS}$ \\
\hline
\end{tabular}

${ }^{*} \mathrm{NS}$ - not significant.

Table 6 - Presence of prominence due to intra-articular anchor.

\begin{tabular}{c|c|c|c}
\hline $\begin{array}{c}\text { Intra-articular } \\
\text { anchor }\end{array}$ & p value & Statistical test & Significance \\
\hline Arthrosis & 1.000 & Chi-square & ${ }^{*} \mathrm{NS}$ \\
\hline Rowe & 0.319 & Mann-Whitney & ${ }^{*} \mathrm{NS}$ \\
\hline Crepitation & 1.000 & Fisher & ${ }^{*} \mathrm{NS}$ \\
\hline${ }^{*} \mathrm{NS}-$ not significant
\end{tabular}

Table 7 - Relationship between sex and termination.

\begin{tabular}{c|c|c|c}
\hline Sex & p value & Statistical test & Significance \\
\hline Arthrosis & 0.370 & Qui-quadrado & ${ }^{*} \mathrm{NS}$ \\
\hline Rowe & 0.612 & Mann-Whitney & ${ }^{*} \mathrm{NS}$ \\
\hline $\begin{array}{c}\text { Renewed } \\
\text { dislocation }\end{array}$ & 0.581 & Fisher & ${ }^{*} \mathrm{NS}$ \\
\hline
\end{tabular}

${ }^{\star} \mathrm{NS}$ - not significant. 
Among the 49 patients of the present study, 40 $(81.6 \%)$ were evaluated radiographically to assess them for glenohumeral arthropathy (Figure 2). The other nine patients did not return with the radiograph that had been requested. Arthropathy was identified in 13 patients (32.5\%), of whom five patients presented grade 1, six grade 2 and two grade 3 (Table 8 ). The presence of arthrosis was statistically significant $(p<0.05)$ in relation to age at the first episode of dislocation and to age at the time of surgical treatment.

The presence of crepitation showed a statistically significant relationship with arthrosis $(p=0.018)$, but not with the presence of intra-articular anchors, while complaints of pain did not present any statistical relationship. There was also no statistically significant association between arthrosis and the interval between the first dislocation and surgery or between arthrosis and the number of dislocations (Table 9).

The dominant side was involved in 33 patients $(67.3 \%)$. Reports of pain occurred in $32.7 \%$ of the cases, among which there were 15 patients $(30.2 \%)$ with occasional mild pain and one $(2.0 \%)$ with complaints of severe pain. Crepitation was found in $34.7 \%$ of the patients.

Evaluation of the postoperative ROM (Figure 3) showed that there was an average loss of $8^{\circ}$ in anterior elevation (range: $92^{\circ}-180^{\circ}$ ) and $12^{\circ}$ in external rotation (range: $30^{\circ}-90^{\circ}$ ) (Table 10 ).

There was no statistically significant direct relationship between the presence of arthrosis of different grades and the Rowe scores (Table 9). Patients with arthrosis of Samilson grade 3 had a mean Rowe score that was greater than among those without arthrosis. No prominences due to anchors were seen in the two cases with grade 3 arthrosis. However, it should be noted that only a small number of cases with grade 3 arthrosis were found $(\mathrm{N}=2)$.

Among the complications resulting from the operation, we identified two cases of adhesive capsulitis and one case of prominence of the synthesis material, which required surgical removal.

\section{DISCUSSION}

Any procedure that has the aim of stabilizing the glenohumeral joint should do so with the minimum of loss of movement.

The first published papers comparing open-surgery stabilization with arthroscopy favored the open

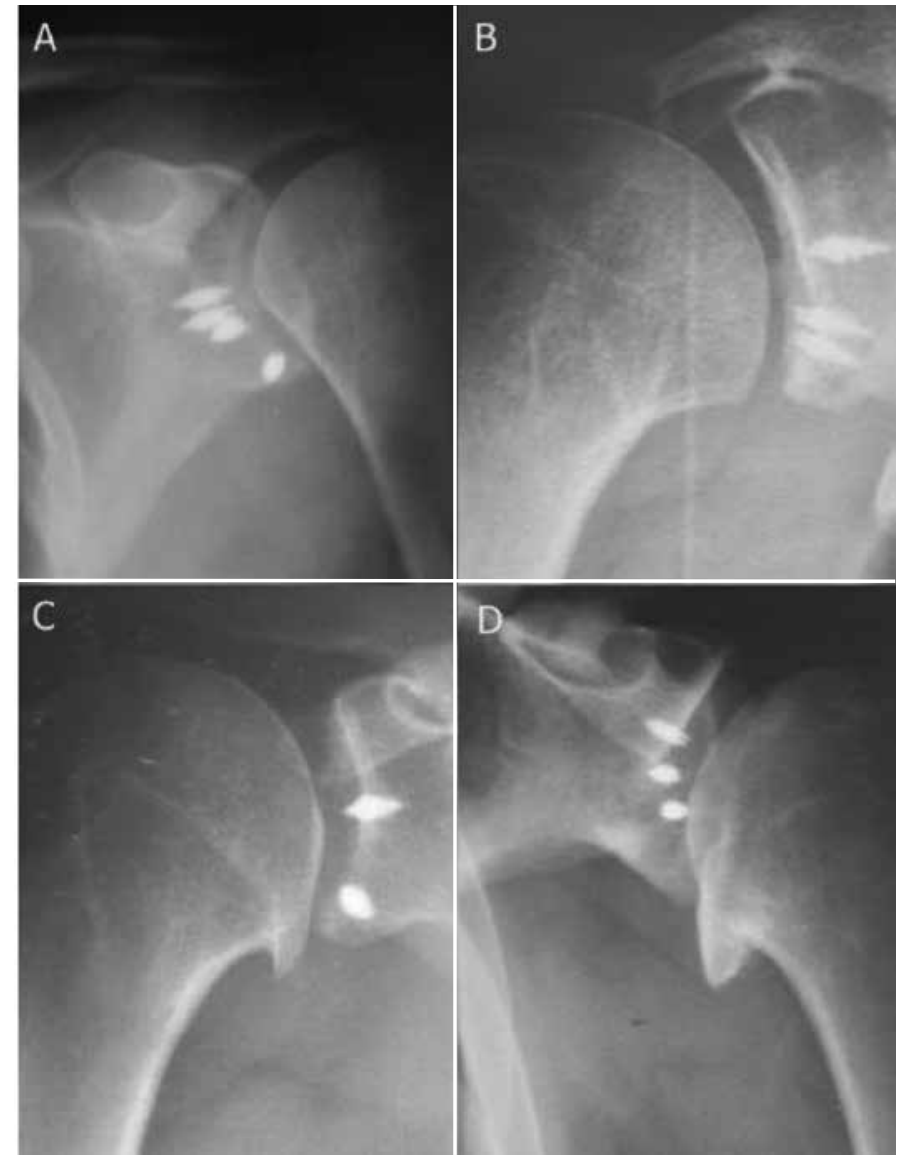

Figure 2 - Glenohumeral degenerative alteration: A) No arthrosis; B) Samilson I; C) Samilson II; and D) Samilson III.

Table 8 - Distribution of postoperative arthropathy according to class and mean age for patient groups.

\begin{tabular}{c|c|c|c}
\hline \multicolumn{2}{l|}{} & $\begin{array}{c}\text { Mean age at first } \\
\text { dislocation }\end{array}$ & $\begin{array}{c}\text { Mean age at time } \\
\text { of surgical } \\
\text { treatment }\end{array}$ \\
\hline Samilson & Number & & \\
\hline $\begin{array}{c}\text { No } \\
\text { arthrosis }\end{array}$ & $27(67.5 \%)$ & 24.1 & 28.5 \\
\hline $\mathbf{1}$ & $5(12.5 \%)$ & 20.8 & 25.8 \\
\hline $\mathbf{2}$ & $6(15 \%)$ & 37.6 & 40.3 \\
\hline $\mathbf{3}$ & $2(5 \%)$ & 39.5 & 49.5 \\
\hline
\end{tabular}

Table 9 - Correlation of mean scores: Rowe versus Samilson.

\begin{tabular}{c|c}
\hline Samilson & Rowe (mean) \\
\hline No arthrosis & 84.1 \\
\hline Grade 1 & 94.0 \\
\hline Grade 2 & 83.3 \\
\hline Grade 3 & 90.0 \\
\hline
\end{tabular}

procedure. Arthroscopic capsulorrhaphy with staples presented a high rate of complications and lack of success $^{(17-19)}$. Transglenoid arthroscopic suture presented variable results $^{(20-25)}$. Usually, this technique presents results that are inferior to open Bankart repair, although Savoie et $\mathrm{l}^{(24)}$ reported achieving acceptable results with this technique. 


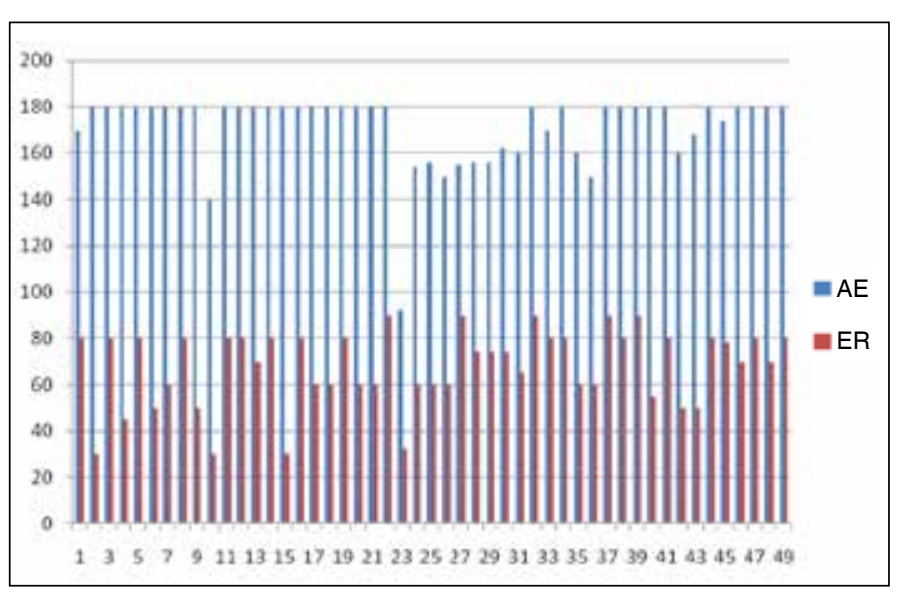

Figure 3 - Anterior elevation $(\mathrm{AE})$ and external rotation (ER) after the operation.

Table 10 - Comparison of pre and postoperative range of motion (ROM).

\begin{tabular}{c|c|c}
\hline ROM & Preoperative & Postoperative \\
\hline AE & $179^{\circ}\left(150^{\circ}-180^{\circ}\right)$ & $171^{\circ}\left(92^{\circ}-180^{\circ}\right)$ \\
\hline ER & $80^{\circ}\left(55^{\circ}-90^{\circ}\right)$ & $68^{\circ}\left(30^{\circ}-90^{\circ}\right)$ \\
\hline
\end{tabular}

Marquardt et al ${ }^{(26)}$ retrospectively evaluated 54 patients who underwent treatment for Bankart lesions by means of reconstruction using anchors. Among their results, they found that instability recurred in $7.5 \%$, and that $85.7 \%$ of the patients returned to their preoperative sports level. Following the same trend, Sadovsk et $\mathrm{al}^{(27)}$ reviewed 77 patients who had been treated arthroscopically and found that $94.8 \%$ of the results were good and excellent, with a renewed dislocation rate of $3.9 \%$.

Koss et al $^{(28)}$ studied 27 patients who had undergone arthroscopic repair of Bankart lesions and reported that $70 \%$ of the results were good and excellent, with $30 \%$ showing renewed dislocation, and less than $10^{\circ}$ loss of external rotation in abduction. Furthermore, Sedeek et $\mathrm{al}^{(29)}$ found that $92.5 \%$ of their results were good, with $7.5 \%$ showing renewed dislocation, from the same technique.

In a prospective evaluation on 40 patients with high functional demands who presented recurrent shoulder dislocation, Bacilla et $\mathrm{l}^{(30)}$ reported that after arthroscopic stabilization with anchors and a mean follow-up of 30 months, there were three cases of renewed dislocation that required a new surgical procedure.

In a series of 167 patients who underwent arthroscopic stabilization of recurrent shoulder dislocation by means of a non-absorbable suture and anchors, Kim et $\mathrm{al}^{(10)}$ reported that $95 \%$ of the results were good or excellent, as assessed using the Carter-Rowe score. The rate of recurrence of instability was $4 \%$, and all these cases were related to glenoid bone lesions involving more than $30 \%$ of the surface of the glenoid cavity, and a mean loss of external rotation of $2^{\circ} \pm 4^{\circ}$.

In 1982, Neer et $\mathrm{al}^{(31)}$ described an association between surgical treatment of shoulder dislocation and degeneration of this joint. In 1983, Samilson and Prieto $^{(32)}$ created the term "arthropathy of instability" and classified this entity radiographically. They also observed that greater age at the time of the first episode and posterior direction greater than anterior direction were factors related to development of postoperative arthrosis.

The incidence of glenohumeral arthrosis following an operation to treat anterior shoulder instability has been reported in several studies in the literature, and this has ranged from $12 \%$ to $62 \%$, depending on the surgical technique used ${ }^{(33-35)}$.

In a series in 1995 , Rosenberg et $\mathrm{al}^{(36)}$ reassessed 31 patients (33 shoulders) who underwent repairs on anterior labral lesions by means of the Bankart procedure in the 1970s and 1980s. After a mean follow-up of 15 years, they observed that $58 \%$ (18 patients) showed radiological abnormalities, as assessed using the Samilson method. With the same surgical procedure, Hovelius et $\mathrm{al}^{(37)}$ reported that after an average of 18 years of follow-up, 63\% presented arthrosis. On the other hand, from evaluations on 54 patients, Chapnikoff et $\mathrm{al}^{(34)}$ found that $20.4 \%$ presented glenohumeral arthrosis after a mean follow-up of 16 years.

From following up patients who underwent the Putti-Platt procedure, Van Der Zwaag et al ${ }^{(38)}$ and Konig et $\mathrm{al}^{(39)}$ reported that the incidence was $61 \%$ after an average of 22 years of follow-up, and 58\% after an average of 26 years of follow-up, respectively.

Using the Latarjet procedure to stabilize recurrent anterior shoulder dislocation, Allain et $\mathrm{al}^{(33)}$ found after a mean follow-up of 14.3 years (range: 10-23 years) that 34 out of 58 shoulders presented glenohumeral arthrosis on radiographic evaluation. Among the cases classified as grade 1, 25 out of 34 did not present abnormalities of shoulder function, which was unlike the higher grades. In an assessment on the same procedure after a mean follow-up of 8.2 years, Dossim et al ${ }^{(40)}$ reported that $9.7 \%$ of their case series presented degenerative alterations. However, $17.2 \%$ presented dislocation and/or instability after the operation. Hovelius et $\mathrm{al}^{(41)}$ described results from 
shoulder stabilization using the Bristow-Latarjet procedure: out of their 115 patients, $40 \%$ presented degeneration (39, mild; five, moderate; and two, severe).

Using Morgan's arthroscopic surgical technique in a series of 79 patients, Godinho et $\mathrm{al}^{(42)}$ found that $13.9 \%$ presented recurrence of dislocation after a mean follow-up of 30 months. From the UCLA score, $82 \%$ of the patients were considered to present excellent results, $4 \%$ good and $14 \%$ poor: the poor group comprised the patients who presented postsurgical recurrence.

Using open suturing of the labrum with metal anchors in a series of 54 patients, Lech et al ${ }^{(43)}$ found that $87.1 \%$ of the results were good or excellent, from the Carter-Rowe score, after an average follow-up of 50 months.

O'Neil ${ }^{(35)}$ used an arthroscopic technique for transglenoid suturing and reported that among the series of 41 patients, the incidence was $12 \%$ over a mean follow-up of 4.5 years.

In a randomized prospective series of 40 patients, Magnusson et $\mathrm{al}^{(44)}$ compared the use of two different arthroscopic techniques for treating Bankart lesions, with bioabsorbable implants (described as "tacks") of either polyglycolic acid (PGACP) or polylactic acid (PLLA), with regard to function and arthroplasty. The patients were evaluated six and 24 months after the operation, and the recurrence rate for dislocation was found to be 5\%. Arthropathy was reported in 30\% (five mild cases and one moderate case) in the PLLA group and 33\% (six mild cases) in the PGACP group. The mean Rowe score was 90 points in both groups.

In a retrospective review on 570 patients, Buscayret et $\mathrm{al}^{(45)}$ reported that the general incidence of glenohumeral arthrosis was $19.7 \%$ after a mean follow-up of 6.5 years after an operation to provide anterior stabilization of the shoulder. In this review, it was concluded that the operation did not directly contribute towards development of the glenohumeral arthrosis but, rather, the contribution was from preoperative risk factors such as older patients, greater numbers of episodes of dislocation and longer duration of postsurgical follow-up. Although diminished external rotation was correlated with the presence of arthrosis, the authors of this study were unable to come to a conclusion regarding the cause-effect relationship between these variables. With regard to the variable of surgical technique, lower arthrosis rates were found with arthroscopic treatment, while higher arthrosis rates were present in open procedures that disturbed soft tissues while the lesions were being repaired.

In the present study, we observed that the incidence of arthropathy was $32.5 \%$ with arthroscopic treatment, after a mean follow-up of 42 months. This is discordant with what was reported by Buscayret et $\mathrm{al}^{(45)}$ in their review, in which incidence of arthrosis in arthroscopic procedures was cited as $8.7 \%$. On the other hand, our result is in line with what was reported by Magnusson et $\mathrm{al}^{(44)}$ (mean incidence of arthropathy of 30\%).

Failure of surgical stabilization, thus resulting in postoperative renewed dislocation, was observed in $16 \%$, and $37.5 \%$ of these cases were considered to be new episodes, after occurrences of major trauma. This percentage failure of stabilization is in agreement with the literature (range from $7.5 \%$ to $30 \%$ ), with regard to repairs using anchors ${ }^{(28-29)}$.

From the Rowe score in our series, we obtained a mean of 83 points, i.e. similar to the 88 points in the series of Koss et $\mathrm{al}^{(28)}$.

\section{CONCLUSION}

Arthroscopic stabilization of recurrent traumatic shoulder dislocation, by means of a reconstruction technique using metal anchors, presented good or excellent functional results in $77.5 \%$ of the cases, and this was associated with low postoperative morbidity. Among the fair and poor results (11 cases), eight were due to renewed dislocation and three of these were consequent to new trauma. The postoperative arthrosis rate $(32.5 \%)$ was relatively high, possibly related to the long follow-up of this study.

\section{REFERENCES}

1. Rowe CR, Patel D, Southmayd WW. The Bankart procedure: a long-term end-result study. J Bone Joint Surg Am. 1978;60(1):1-16.

2. Perthes G. [Über Operationen bei habitueller Schulterluxation]. Dtsch Z Chir. 1906;56:149-51.

3. Bankart AS. Recurrent or habitual dislocation of the shoulder-joint. Br Med J. 1923;2(3285):1132-3

4. Baker CL, Uribe JW, Whitman C. Arthroscopic evaluation of acute initial anterior

shoulder dislocations. Am J Sports Med. 1990;18(1):25-8.

5. Moseley HF, Overgaard B. The anterior capsular mechanism in recurrent anterior dislocation of the shoulder: Morphological and clinical studies with special reference to the glenoid lábio and the glenohumeral ligaments. J Bone Joint Surg Br. 1962;44:913-27.

6. O'Brien SJ, Neves MC, Arnoczky SP, Rozbruck SR, Dicarlo EF, Warren RF, et al. The anatomy and histology of the inferior glenohumeral ligament complex 
of the shoulder. Am J Sports Med. 1990;18(5):449-56.

7. Galinat BN, Howel SM. The containment mechanism: the primary stabilizer of the glenohumeral joint. In: 45th AAOS Meeting, San Francisco, CA, USA, January 1987.

8. Turkel SJ, Panio MW, Marshall JL, Girgis FG. Stabilizing mechanisms preventing anterior dislocation of the glenohumeral joint. J Bone Joint Surg Am. 1981;63(8):1208-17.

9. Trenhaile SW, Savoie FH 3rd. New frontiers in arthroscopic treatment of glenohumeral instability. Arthroscopy. 2002;18(2 Suppl 1):76-87.

10. Kim SH, Ha KI, Cho YB, Ryu BD, Oh I. Arthroscopic anterior stabilization of the shoulder: two to six-year follow-up. J Bone Joint Surg Am. 2003;85(8):1511-8.

11. Green MR, Christensen KP. Arthroscopic Bankart procedure: two- to five-year followup with clinical correlation to severity of glenoid labral lesion. Am J Sports Med. 1995;23(3):276-81.

12. Ryu RK. Arthroscopic approach to traumatic anterior shoulder instability. Arthroscopy. 2003;19(Suppl 1):94-101.

13. Sperling JW, Smith AM, Cofield RH, Barnes S. Patient perceptions of open and arthroscopic shoulder surgery. Arthroscopy. 2007;23(4):361-6

14. Fabbriciani C, Milano G, Demontis A, Fadda S, Ziranu F, Mulas PD. Arthroscopic versus open treatment of Bankart lesion of the shoulder: a prospective randomized study. Arthroscopy. 2004;20(5):456-62.

15. Kim SH, Ha KI, Kim SH. Bankart repair in traumatic anterior shoulder instability: open versus arthroscopic technique. Arthroscopy. 2002;18(7):755-63

16. Cole BJ, L'Insalata J, Irrgang J, Warner JJ. Comparison of arthroscopic and open anterior shoulder stabilization. A two to six-year follow-up study. J Bone Joint Surg Am. 2000;82(8):1108-14.

17. Coughlin L, Rubinovich M, Johansson J, White B, Greenspoon J. Arthroscopic staple capsulorrhaphy for anterior shoulder instability. Am J Sports Med. 1992;20(3):253-6.

18. Lane JG, Sachs RA, Riehl B. Arthroscopic staple capsulorrhaphy: a long-term follow-up. Arthroscopy. 1993;9(2):190-4

19. Matthews LS, Vetter WL, Oweida SJ, Spearman J, Helfet DL. Arthroscopic staple capsulorrhaphy for recurrent anterior shoulder instability. Arthroscopy. 1988;4(2):106-11.

20. Grana WA, Buckley PD, Yates CK. Arthroscopic Bankart suture repair. Am J Sports Med. 1993;21(3):348-53.

21. Green MR, Christensen KP. Arthroscopic Bankart procedure: two- to five-year followup with clinical correlation to severity of glenoid labral lesion. Am J Sports Med. 1995;23(3):276-81.

22. Morgan CD, Bodenstab AB. Arthroscopic Bankart suture repair: technique and early results. Arthroscopy. 1987;3(2):111-22.

23. Pagnani MJ, Warren RF, Altchek DW, Wickiewicz TL, Anderson AF. Arthroscopic shoulder stabilization using transglenoid sutures. A four-year minimum followup. Am J Sports Med. 1996;24(4):459-67.

24. Savoie FH 3rd, Miller CD, Field LD. Arthroscopic reconstruction of traumatic anterior instability of the shoulder: the Caspari technique. Arthroscopy. 1997;13(2):201-9.

25. Torchia ME, Caspari RB, Asselmeier MA, Beach WR, Gayari M. Arthroscopic transglenoid multiple suture repair: 2 to 8 year results in 150 shoulders. Arthroscopy. 1997;13(5):609-19.

26. Marquardt B, Witt KA, Liem D, Steinbeck J, Pötzl W. Arthroscopic Bankart re- pair in traumatic anterior shoulder instability using a suture anchor technique. Arthroscopy. 2006;22(9):931-6.

27. Sadovsk Ã P, Musil D, StehIÃk J. Arthroscopic stabilization of the shoulder. Acta Chir Orthop Traumatol Cech. 2006;73(1):23-7.

28. Koss S, Richmond JC, Woodward JS Jr. Two- to five-year followup of arthroscopic Bankart reconstruction using a suture anchor technique. Am J Sports Med. 1997;25(6):809-12.

29. Sedeek SM, Tey IK, Tan AH. Arthroscopic Bankart repair for traumatic anterior shoulder instability with the use of suture anchors. Singapore Med J. 2008;49(9):676-81.

30. Bacilla P, Field LD, Savoie FH 3rd. Arthroscopic Bankart repair in a high demand patient population. Arthroscopy. 1997;13(1):51-60

31. Neer CS 2nd, Watson KC, Stanton FJ. Recent experience in total shoulder replacement. J Bone Joint Surg Am. 1982;64(3):319-37.

32. Samilson RL, Prieto V. Dislocation arthropathy of the shoulder. J Bone Joint Surg Am. 1983;65(4):456-60.

33. Allain J, Goutallier D, Glorion C. Long-term results of the Latarjet procedure for the treatment of anterior instability of the shoulder. J Bone Joint Surg Am. 1998;80(6):841-52.

34. Chapnikoff D, Besson A, Chantelot C, Fontaine C, Migaud H, Duquennoy A. [Bankart procedure: clinical and radiological long-term outcome]. Rev Chir Orthop Reparatrice Appar Mot. 2000;86(6):558-65.

35. O'Neil DB. Arthroscopic Bankart repair of anterior detachments of the glenoid labrum: a prospective study. J Bone Joint Surg Am. 1999;81(10):1357-66.

36. Rosenberg BN, Richmond JC, Levine WN. Long-term followup of Bankart reconstruction. Incidence of late degenerative glenohumeral arthrosis. Am J Sports Med. 1995;23(5):538-44

37. Hovelius LK, Sandström BC, Rösmark DL, Saebö M, Sundgren KH, Malmqvist BG. Long-term results with the Bankart and Bristow-Latarjet procedures: recurrent shoulder instability and arthropathy. J Shoulder Elbow Surg. 2001;10(5):445-52.

38. van der Zwaag HM, Brand R, Obermann WR, Rozing PM. Glenohumeral osteoarthrosis after Putti-Platt repair. J Shoulder Elbow Surg. 1999;8(3):252-8.

39. Konig DP, Rutt J, Treml O, Kausch T, Hackenbroch MH. Osteoarthrosis following the Putti-Platt operation. Arch Orthop Trauma Surg. 1996;115(3-4):231-2.

40. Dossim A, Abalo A, Dosseh E, Songne B, Ayite A, Gnandi-Pio F. [Bristow-Latarjet repairs for anterior instability of the shoulder: clinical and radiographic results at mean 8.2 years follow-up]. Chir Main. 2008;27(1):26-30.

41. Hovelius L, Sandström B, Saebö M. One hundred eighteen Bristow-Latarjet repairs for recurrent anterior dislocation of the shoulder prospectively followed for fifteen years: study II-the evolution of dislocation arthropathy. J Shoulder Elbow Surg. 2006;15(3):279-89.

42. Godinho GG, Souza JMG, Freitas JMA, Santos FML, Vieira AW, João FM. Tratamento da instabilidade anterior do ombro experiência com a técnica de Morgan. Rev Bras Ortop. 1997;32(4):265-71.

43. Lech O, Pinto Júnior SC, Severo A. O uso de âncoras no reparo aberto da luxação anterior recidivante do ombro. Rev Bras Ortop. 2003;38(11/12):654-66.

44. Magnusson L, Ejerhed L, Rostgård-Christensen L, Sernert N, Eriksson R, Karlsson $\mathrm{J}$, et al. A prospective, randomized, clinical and radiographic study after arthroscopic Bankart reconstruction using 2 different types of absorbable tacks. Arthroscopy. 2006;22(2):143-51.

45. Buscayret F, Edwards TB, Szabo I, Adeleine P, Coudane H, Walch G. Glenohumeral arthrosis in anterior instability before and after surgical treatment: incidence and contributing factors. Am J Sports Med. 2004;32(5):1165-72. 